\title{
GAMBARAN ULTRASONOGRAFI PLAK ARTERI KAROTIS
}

\author{
Dedi Sutia $^{1}$, Syarif Indra ${ }^{1}$, Hendra Permana ${ }^{1}$, Rizki Muhammad Rananda ${ }^{2}$ \\ ${ }^{1}$ Bagian Neurologi RSUP Dr. M. Djamil Padang/Universitas Andalasama \\ email: dr.dedisutia@gmail.com \\ ${ }^{2}$ Nprogram Pendidikan Dokter Spesialis,Fakultas Kedokteran, Universitas Andalas/RSUP Dr. M. Djamil Padang , \\ email: rizkirananda@gmail.com
}

Submitted: 02-04-2020, Reviewer: 07-04-2020, Accepted: 07-04-2020

\begin{abstract}
Duplex Carotid Ultrasonography is non invasive and friendly examination, used to observe carotid artery. About 20-30\% from total stroke cases, caused by extracranial carotid artery abnormalities. Atherosclerosis plaque at carotid artery is suspected as the etiology for more than $80 \%$ cerebral thromboembolism. Aim : to find out ultrasonography image at carotid artery plaque. Method : the method of this study is literature review towards experimental articles which were published internationally at Pubmed / Medline database from 1977 - 2015. The literature study is arranged based on Walker and Avant guideline, which is consist of : a) conceptual comprehension; b) aim or role identification; c) concept identification and the relation with role and aim. Result : carotid artery ultrasonography examination covers common carotid artery, proximal internal and external carotid artery analysis. Parts to notice are artery diameter, carotid bulbous, intimal medial thickness, flow velocity, type of wave, present of plaque, also artery abnormalities, such as dysplasia, coiling, kinking, and tortuosity. Conclusion : atherosclerosis plaque imaging with conventional ultrasonography is a relative easy, affordable and non invasive technique with specificity and sensitivity level equal with other imaging modalities.
\end{abstract}

Keywords: Ultrasonography, carotid artery plaque, atherosclerosis

\begin{abstract}
Abstrak
Pemeriksaan ultrasonografi carotid duplex merupakan pemeriksaan yang tidak invasif dan mudah digunakan untuk menilai arteri karotis sampai sekarang ini. Sebanyak 20-30\% dari total kasus stroke diakibatkan oleh kelainan pada arteri karotis ekstrakranial. Adanya plak aterosklerosis pada arteri carotis diduga sebagai penyebab lebih dari $80 \%$ kasus tromboemboli serebri. Tujuan: untuk mengetahui gambaran ultrasonografi pada plak arteri karotis. Metode: Jenis penelitian yang dilakukan dengan menggunakan desain literature review terhadap artikel penelitian yang terpublikasi secara internasional pada database Pubmed/Medline dari tahun 1977-2015. Studi literatur ini disusun berdasarkan panduan Walker dan Avant yang terdiri dari pengkajian yaitu: a) pemahaman konsep; (b) identifikasi peran atau tujuan; (c) mengidentifikasi semua konsep dan kaitannya dengan peran atau tujuan. Hasil: Pemeriksaan ultrasonografi arteri karotis meliputi analisis arteri karotis komunis, arteri karotis interna proksimal dan arteri karotis eksterna proksimal. Yang diamati antara lain adalah diameter arteri, bulbus karotis, intimal medial thickness, kecepatan aliran, bentuk gelombang, keberadaan plak serta kelainan lain pada arteri seperti dysplasia, coiling, kinking dan tortuosity. Simpulan: Pencitraan plak aterosklerosis dengan ultrasonografi konvensional merupakan teknik yang relatif mudah, murah dan noninvasif dengan level sensitifitas dan spesifisitas yang setara dengan modalitas pemeriksaan pencitraan lainnya.
\end{abstract}

Kata kunci: Ultrasonografi, plak arteri karotis, aterosklerosis

\section{PENDAHULUAN}

Stroke iskemik diperkirakan sampai $85 \%$ dari total seluruh kejadian stroke. Kejadian stroke iskemik ini tidak terlepas dari proses aterosklerosis yang terjadi di pembuluh darah. ${ }^{1} \quad$ Aterosklerosis dari arteri yang mensuplai sistem saraf pusat akan menyebabkan stroke atau TIA. Stroke iskemik dapat terjadi karena arterosklerosis pembuluh darah kecil seperti arteri 
lentikulostriata dan arteri penetrating namun juga dapat mengenai pembuluh darah besar seperti arteri karotis. ${ }^{2}$ Diperkirakan sebanyak 20\% kasus stroke iskemik berkaitan dengan aterosklerosis di bifurkasio karotis yang menyebabkan sumbatan (stenosis). Aterosklerosis arteri karotis merupakan kelainan dengan pathogenesis yang kompleks dengan melibatkan berbagai faktor resiko mulai genetik, hipertensi, merokok, diabetes, dyslipidemia dan hiperhomosisteinemia. ${ }^{3,4}$

Kaitan antara stenosis arteri karotis dengan stroke pertama kali dilaporkan oleh Savory pada tahun 1856. Kejadian stroke diakibatkan karena adanya oklusi dari plak aterosklerosis. Walaupun sudah diketahui sedah sejak lama, namun pendekatan diagnosis dan penatalaksanaan terhadap kelainan pada arteri karotis masih menjadi tantangan besar bagi para klinisi sampai saat ini. Berbagai modalitas diagnostik mulai dari yang non invasif seperti teknik duplex ultrasound, computed tomography, magnetic resonance imaging sampai ke teknik yang invasif seperti angiografi. Masing-masing modalitas memiliki kelebihan dan kekurangan dalam mendeteksi plak arterosklerosis pada arteri karotis dan resikonya dalam menyebabkan stroke di kemudian hari. ${ }^{5}$ Sampai saat ini, pendekatan penatalaksanaan terhadap sumbatan arteri karotis yang disebabkan oleh plak aterosklerosis juga masih menjadi perdebatan para ahli sampai saat ini antara carotid endarterectomy dan stenting karotis. Tidak hanya itu masalah timing beranjak dari penatalaksanaan medikamentosa menjadi penatalaksanaan invasif juga masih menjadi perdebatan. ${ }^{6}$ Guideline ASA/AHA pada tahun 2011 menyebutkan bahwa derajat stenosis $(\geq 70 \%$ pada carotid duplex atau $\geq 50 \%$ pada angiografi) merupakan satu-satunya pertimbangan untuk dilakukannya tindakan intervensi pada sumbatan arteri karotis. Namun banyak penelitian menemukan bahwa stroke related extracranial carotid artery disease banyak terjadi bahkan pada derajat stenosis kurang dari $50 \%$ pada pemeriksaan carotid dupplex. Terjadinya stroke pada pasien dengan penyakit arteri karotis diduga disebabkan tidak hanya semata-mata oleh meningkatnya derajat stenosis tapi juga dipengaruhi oleh berbagai faktor lain seperti ekogenitas dan tektur dari plak arteri karotis tersebut. ${ }^{7,8}$ Oleh karena itu penulis ingin membuat sebuah referat tentang gambaran ultrasonografi plak pada arteri karotis untuk meningkatkan pengetahuan tentang kelainan pada arterosklerosis dan sebagai salah satu syarat dalam menyelesaikan fellowship di subdivisi stroke-neurosonologi.

\section{METODE PENELITIAN}

Jenis penelitian yang dilakukan dengan menggunakan desain literature review terhadap artikel penelitian yang terpublikasi secara internasional pada database Pubmed/Medline dari tahun 1977-2015. Pengumpulan data dilakukan dengan menggunakan pencarian secara online dengan menggunakan kata kunci: "ultrasonography AND carotid artery plaque". Studi literatur ini disusun berdasarkan panduan Walker dan Avant yang terdiri dari pengkajian yaitu: a) pemahaman konsep; (b) identifikasi peran atau tujuan; (c) mengidentifikasi semua konsep dan kaitannya dengan peran atau tujuan.

\section{HASIL DAN PEMBAHASAN}

\section{Pemeriksaan ultrasonografi arteri karotis}

Pemeriksaan ultrasonografi carotid duplex merupakan pemeriksaan yang tidak invasif dan mudah digunakan untuk menilai arteri karotis sampai sekarang ini. Alat yang digunakan biasanya sebuah alat USG dengan menggunakan probe linear dengan frekuensi 5-7 $\mathrm{MHz}$. Tranduser dengan frekuensi $5 \mathrm{MHz}$ biasanya digunakan untuk analisis rutin arteri karotis, sedangkan tranduser $7 \mathrm{MHz}$ digunakan untuk 
penilaian lebih detail tentang kelainan pada daerah tunika intima. Pada saat pemeriksaan pasien berada pada posisi telentang dengan kepala sedikit diekstensikan serta menoleh sedikit ke arah kontralateral dengan arteri yang diperiksa. Ekstensi atau rotasi kepala tidak boleh lebih dari $45^{0}$ karena akan menyebabkan kontraksi otot sternokleidomastoideus yang nantinya akan mempersulit proses pemeriksaan. Pemeriksaan ini dapat dilakukan pada 2 posisi yaitu pemeriksa berada di bagian atas dari kepala pasien atau pemeriksa berada di samping pasien. Posisi tranduser yang digunakan pada analisis arteri karotis bisa dengan longitudinal ataupun secara transversal. Pencitraan arteri karotis dapat dengan memposisikan tranduser di daerah anterior, lateral, anterolateral dan posterolateral. ${ }^{9,10,11}$

Arteri karotis interna terletak pada daerah posterolteral sendangkan arteri karotis eksterna terletak di arah anterior. Arteri karotis eksterna memiliki banyak cabang sedangkan arteri karotis interna tidak memiliki cabang di daerah ekstrakranial. Dari segi ukuran, arteri karotis interna lebih besar dari arteri karotis eksterna. Gambaran gelombang arteri karotis interna juga berbeda dengan arteri karotis eksterna di mana gelombang pada arteri karotis interna memiliki resistensi yang rendah sehingga jarak antara sistolik dan diastolik juga rendah, sebaliknya arteri karotis eksterna memiliki puncak sistolik yang lebih tajam dengan diastolik yang lebih rendah. Cara lain untuk membedakan antara kedua arteri di atas adalah dengan menggunakan manuver "temporal tapping". Teknik ini dilakukan dengan menekan arteri temporalis superfisialis dan melihat perubahan pola gelombang pada layar monitor. Pemeriksaan ultrasonografi arteri karotis meliputi analisis arteri karotis komunis, arteri karotis interna proksimal dan arteri karotis eksterna proksimal. Yang diamati antara lain adalah diameter arteri, bulbus karotis, intimal medial thickness, kecepatan aliran, bentuk gelombang, keberadaan plak serta kelainan lain pada arteri seperti dysplasia, coiling, kinking dan tortuosity. ${ }^{9,10,11}$

Table 1. Perbedaan Ultrasonografi Arteri Karotis $^{9}$

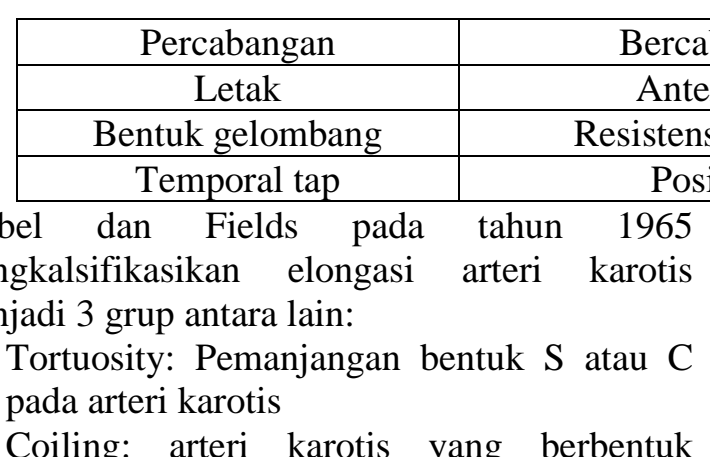

2. Coiling: arteri karotis yang berbentuk sirkular (lilitan)

3. Kinking: angulasi satu atau lebih segmen arteri karotis yang berhubungan dengan terjadinya stenosis.

Tortuosity, coiling dan kinking ini biasanya bersifat kongenital dan dapat diamati dengan pemeriksaan ultrasonografi pada usia anak-anak. Hasil pengamatan Webel dan Fields pada 1046 pasien didapatkan tortuosity sebanyak $15 \%$, coiling 3\% dan kinking 0,5\%. Kelainan-kelainan ini telah dilaporkan berhubungan dengan berbagai kejadian stroke dan TIA terkait perubahan hemodinamik yang disebabkannya, namun sampai saat ini hal tersebut masih menjadi perdebatan. Kelainan ini dapat menyebabkan kompresi struktur anatomis yang berdekatan. Pernah dilaporkan kompresi nervus hipoglossus pada tutousity arteri karotis. ${ }^{12,13}$ Hasil pengamatan Hoskins et al pada 220 pasien mendapatkan bahwa tortuosity paling banyak ditemukan pada daerah $3 \mathrm{~cm}$ pertama setelah percabangan arteri karotis interna dan dianjurkan untuk pemeriksaan totuosity cukup 2 sampai 3 $\mathrm{cm}$ dati proksimal arteri karotis interna ${ }^{9,14}$.

Untuk mendapatkan sinyal ultrasound yang maksimal pada pemeriksaan dengan color doppler dan spectral doppler, pemeriksaan dilakukan pada posisi longitudinal (posisi yang perpendicular dengan arah aliran). Semakin kecil sudut antara sinyal Doppler dengan arah aliran maka akan semakin tinggi frekuensi yang dapat ditangkap oleh tansduser dan semakin sensitif hasil pemeriksaan yang dilakukan. Pada sudut 60 sampai $90^{\circ}$ frekuensi Doppler dan velocity akan semakin kecil dan tidak menggambarkan pola aliran yang sebenarnya. Oleh karena itu pada pemeriksaan carotid duplex sudut yang digunakan tidak boleh lebih dari $60^{\circ}$ untuk menghindari kesalahan interpretasi. ${ }^{14,15}$

\begin{tabular}{|c|c|c|}
\hline Perbedaan & Arteri Karotis Eksterna & Arteri karotis Interna \\
\hline Ukuran & Lebih kecil & Lebih besar \\
\hline
\end{tabular}


Tabel 2. Panduan dalam analisis aliran pada carotid duplex ${ }^{14}$
\begin{tabular}{|c|c|c|}
\hline Pengaturan & $\begin{array}{c}\text { Evaluasi } \\
\text { aliran } \\
\text { (menentuka } \\
\text { n stenosis) }\end{array}$ & $\begin{array}{c}\text { Evaluasi } \\
\text { pembulu } \\
\text { h darah } \\
\text { kecil } \\
\text { (aliran } \\
\text { lambat) }\end{array}$ \\
\hline PRF & $\begin{array}{c}\text { Semakin } \\
\text { tinggi } \\
\text { semakin baik }\end{array}$ & Rendah \\
\hline $\begin{array}{c}\text { Color } \\
\text { Box(ukuran } \\
\text { kotak) }\end{array}$ & Kecil & Besar \\
\hline $\begin{array}{c}\text { Angle } \\
\text { Doppler(sudut } \\
\text { ) }\end{array}$ & $\begin{array}{c}\text { Kurang dari } \\
60^{0}\end{array}$ & $\begin{array}{c}\text { Kurang } \\
\text { dari } 60^{0}\end{array}$ \\
\hline Wall filter & Sedang & Sedang \\
\hline Gain & Sedang & Tinggi \\
\hline
\end{tabular}

Selanjutnya, pemeriksaan yang tidak boleh dilewatkan pada evaluasi arteri karotis dengan mengguankan ultrasonografi adalah pengukuran intimal medial thickening (IMT). Pengukuran IMT dapat dilakukan pada dua tempat yaitu pada dinding jauh (far wall) distal arteri karotis kommunis kira-kira $1 \mathrm{~cm}$ sebelum bulbus karotis dan proksimal arteri karotis interna kira-kira 1 $\mathrm{cm}$ setelah percabangan. Pengukuran dilakukan dengan visualisasi secara longitudinal. Intimal medial thickening (IMT) dikatakan abnormal apabila ketebalannya melebihi $1 \mathrm{~mm}^{16}$.

\section{Pemeriksaan plak arteri karotis dengan ultrasonografi}

Plak arteri karotis adalah penebalan lokal tunika intima yang melebihi $1 \mathrm{~mm}$. Visualisasi dengan grey scale atau B-mode paling mudah digunakan dalam memvisualisasi plak dan penebalan abnormal dari tunika intima arteri karotis. Visualisasi plak harus dikonfirmasi dalam dua posisi baik longitudinal maupun transversal untuk mencegah gambaran positif palsu atau overestimasi diameter plak. ${ }^{11}$
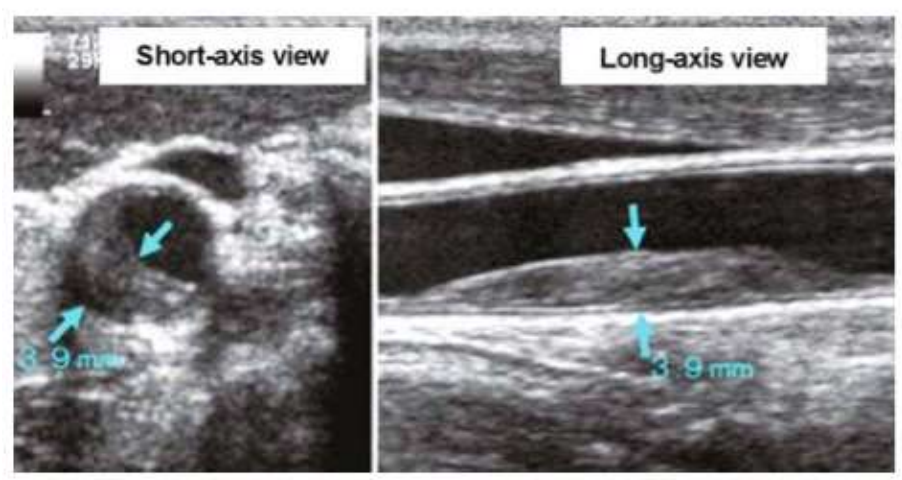

Gambar 1. Pemeriksaan Ultrasonografi Plak Arteri Karotis ${ }^{11}$

Gambaran plak pada pemeriksaan carotid doppler harus mencakup deskripsi antara lain:

\section{Lokasi plak}

Deskripsi lokasi plak biasanya dengan menyebutkan arteri tempat menempelnya plak apakah di arteri karotis kommunis, arteri karotis interna atau di bulbus karotis. Lokasi dinding tempat menempelnya plak juga dideskripsikan apakah di near wall atau di far wall.

Prevalensi plak arteri karotis tidak jauh berbeda antara laki-laki dan perempuan walaupun sedikit lebih tinggi pada laki-laki (55,4\% vs $45,8 \%)$. Plak arteri karotis paling banyak ditemukan pada far wall bulbus karotis baik pada laki-laki maupun perempuan $(40,3 \%$ dan $32,3 \%)$, diikuti dengan arteri karotis interna (13\% dan $17 \%)$ dan frekuensi paling sedikit terdapat pada near wall arteri karotis kommunis (2,55 dan 1,9\%). Joakimsen et al menemukan Soft plaque pada $37 \%$ kasus dan temuan ini menurun seiring bertambahnya umur. Pada subjek dengan multiple plaque, hanya sekitar $15 \%$ saja lokasi plak yang terletak diluar bulbus karotis ${ }^{15,17}$.

\section{Ketebalan plak}

Ketebalan plak diukur dari puncak yang paling tinggi sampai ke dasar plak $^{18}$.

Komposisi plak (ekogenitas, kalsifikasi,
vaskularisasi)
Pada tahun 1985 Johnson mengklasifikasikan
plak aterosklerosis pada pemeriksaan doppler
vascular menjadi hard plaque (high echoes), soft
plaque (low echoes) dan calcified plaque. 
Peneliti lainnya Relly et al pada tahun 1982 mengklasifikasikan plak menjadi plak homogen dan plak heterogen. Plak homogen dikategorikan sebagai plak yang tingkat ekogenitasnya sama dengan level ekogenitas medium sampai tinggi.
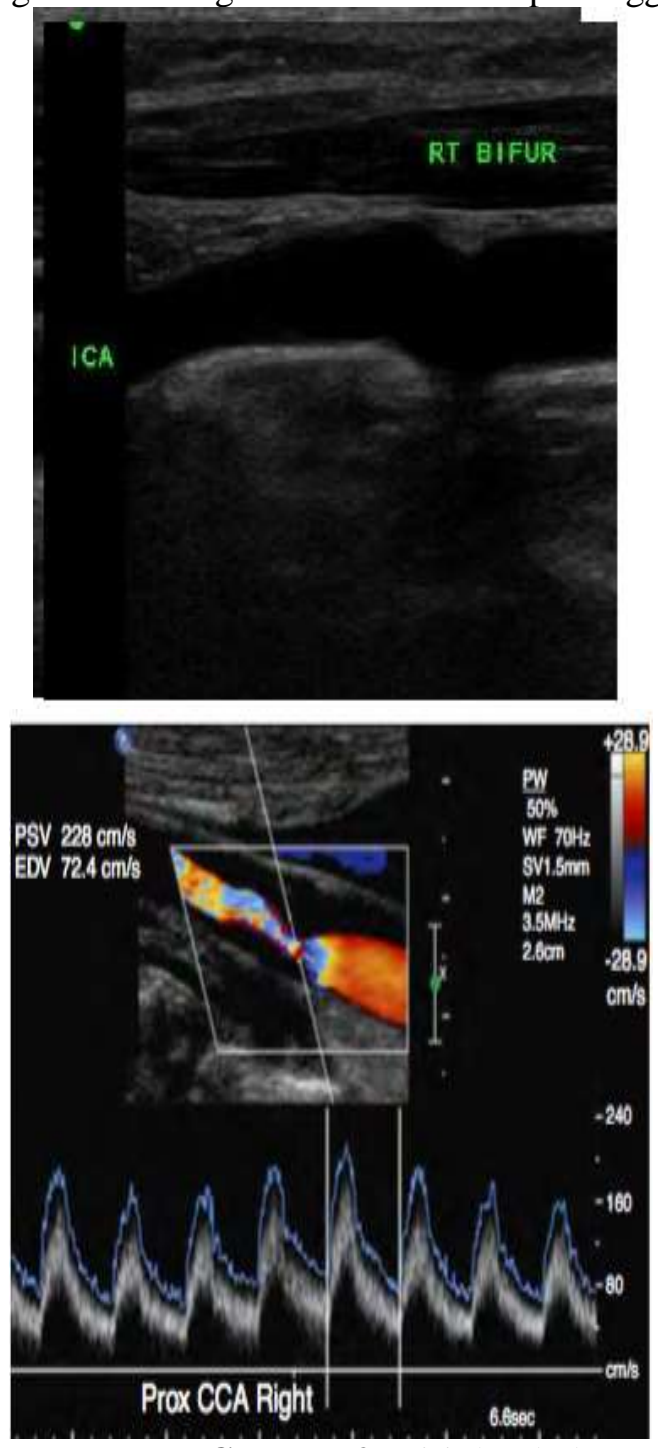

Gambar 2. Kiri: hard plaque

dengan acoustic shadow dan kanan: soft plaque yang sangat hipoekoik

Secara histologi plak homogen ini berkaitan dengan lesi fibrous. Ekogenitas plak akan meningkat sesuai dengan akumulasi kolagen. Plak heterogen dikatergorikan sebagai plak yang memiliki tingkat ekogenitas yang bervariasi mulai dari yang rendah, sedang sampai tingkat ekogenitas yang tinggi. Secara histologi, plak heterogen ini dihubungkan perdarahan intraplak, material lipid dan area nekrotik. Namun demikian, hasil temuan penelitian di tahun-tahun berikutnya mendapatkan komposisi histologis dari berbagai ekogenitas plak ternyata bervariasi satu sama lain. Pada tahun 1988, Grey-Weale et al mengklasifikasikan plak aterosklerosis pada pemeriksaan B mode menjadi 4 tipe yaitu tipe 1 (predominan ekolusen dengan kapsul yang sangat tipis), tipe 2 (predominan ekolusen disertai dengan daerah ekogenik yang minimal yaitu kurang dari 25\%), tipe 3 (predominan ekogenik disertai dengandaerah ekolusen yang minimal yaitu kurang dari 25\%) dan tipe 4 (plak ekogenik atau disebut juga plak homogen). Klasifikasi ini sekarang paling sering digunakan secara umum dan peneliti lain Geroulakos menambahkan klasifikasi tambahan yaitu tipe 5 (plak dengan gambaran acustic shadow). Selanjutnya, Polak et al mengklasifikasikan plak menjadi 3 kategori antara lain plak hipoekoik, isoekoik dan plak hiperekoik ${ }^{19,20,21}$.

Tabel 3. Klasifikasi Plak Arteri Karotis Menurut Grey-Weale. ${ }^{20}$

\begin{tabular}{|c|c|}
\hline $\begin{array}{c}\text { Tipe } \\
\text { plaque }\end{array}$ & Karakteristik Ultrasound \\
\hline Tipe 1 & Predominan hipoekoik \\
\hline Tipe 2 & $\begin{array}{c}\text { Dominan hipoekoik dengan } \\
\text { sedikit area ekogenik }\end{array}$ \\
\hline Tipe 3 & $\begin{array}{c}\text { Dominan hiperekoik } \\
\text { dengan sedikit area } \\
\text { ekolusen }(<25 \%)\end{array}$ \\
\hline Tipe 4 & Hiperekoik (homogen) \\
\hline
\end{tabular}

Klasifikasi menurut Polak ini, pada pemeriksaan B mode acuan hipoekoik adalah ekogenitas dari lumen pembuluh darah dan isoekoik adalah konsistensi otot sternokleidomastoideus serta hiperekoik adalah gambaran intimal-adventesia. Klasifikasi oleh Polak ini dinilai yang paling mudah digunakan karena memiliki variasi interobserever yang lebih seragam dengan nilai kappa 0,95. Daerah hipoekoik pada plak bisa jadi merupakan perdarahan intraplak, deposit lipid atau area nekrotik. Kalsifikasi pada plak memberikan gambaran hiperekoik yang biasanya diikuti gambaran acustic shadow ${ }^{19,20,21}$.. 

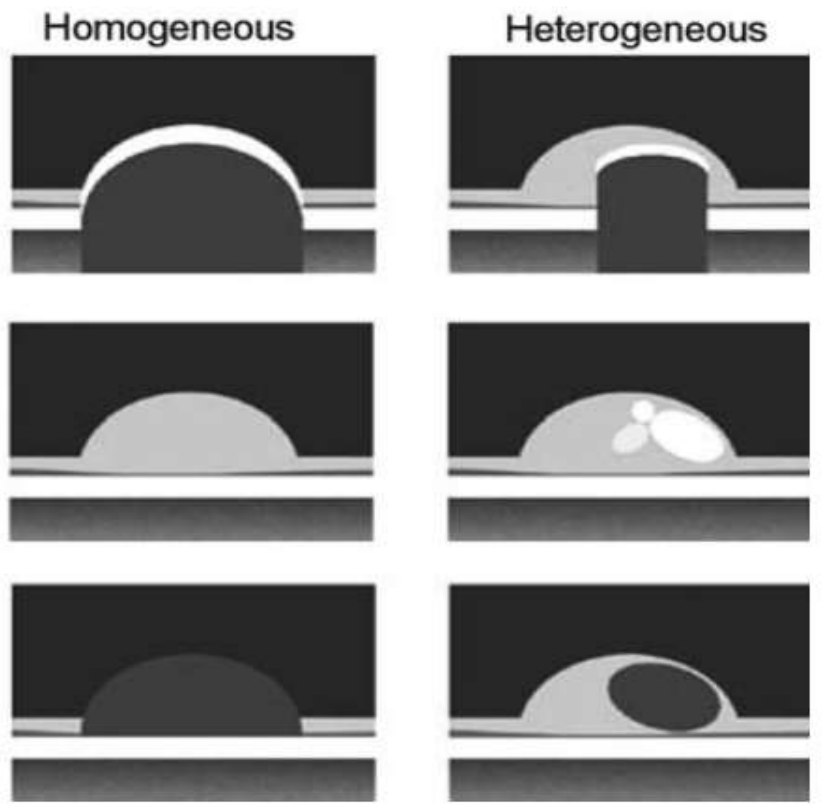

Gambar 3. Klasifikasi Plak Arteri Karotis Berdasarkan Derajat Ekogenitas. ${ }^{21}$

\section{Permukaan plak}

Permukaan plak dinilai apakah rata, iregular atau ulseratif. Plak dikatakan ulseratif apabila memiliki 3 kriteria antara lain memiliki kedalaman $2 \mathrm{~mm}$ dari permukaannya, memiliki lebar minimal $2 \mathrm{~mm}$ dan memiliki dinding dengan batas tegas serta terdapat reversed flow. Analisis plak yang mengalami ulserasi disarankan di visualisasikan dari berbagai sudut. Deteksi permukaan plak sulit hanya dengan metode B mode saja, oleh karena itu disarankan penggunaan color doppler atau power doppler dalam membantu mengidentifikasi permukaan plak. Pada permukaan plak yang rata akan tampak aliran yang teratur dengan menggunakan color Doppler atau power dopler, sedangkan pada plak yang ireguler dan ulsersatif akan tampak aliran yang tidak rata bahkan dapat terlihat reversed flow pada penampang tranversal dan longitudinal, tentunya setelah pemeriksa menyingkirkan efek aliasing ${ }^{8}$.

Penggunaan metode color flow imaging dan power Doppler imaging sangat membantu dalam memvisualisasi adanya plak yang hipoekoik dan thrombus dengan derajat stenosis tinggi. Sebuah riset yang dilakukan O'Donel et al mendapatkan Deteksi kelainan permukaan plak dengan menggunakan carotid Doppler dinilai lebih baik dibandingkan angiografi dengan sensitifitas 89\%

\author{
Kalsifikasi \\ dan \\ hiperekoik
}

\section{Isoekoik}

Hinoekoik vs $59 \%$ dan spesifisitas $87 \%$ vs $73 \%$. Comerota et al melaporkan bahwa ternyata derajat stenosis juga mempengaruhi kemampuan deteksi terhadap kelainan permukaan plak. Penggunaan B mode memiliki sensitifitas $77 \%$ dalam mendeteksi ulserasi pada plak dengan derajat stenosis kurang dari $50 \%$ dan sensitifitas menurun menjadi $41 \%$ pada plak dengan stenosis lebih dari 50\%. Nilai sensitifitas semakin menurun menjadi $33 \%$ pada plak dengan stenosis melebihi $70 \%$. Hasil yang hamper sama didapatkan pada pemeriksaan angiografi ${ }^{6,8}$.

\section{Derajat stenosis}

Tujuan utama penggunaan ultrasonografi adalah untuk menentukan adanya stenosis pada arteri karotis karena lebih dari 30\% kejadian stroke hemisfer berasal dari kelainan pada arteri karotis. Kejadian stenosis terbanyak terdapat pada bagian proksimal arteri karotis interna. Penggunaan teknik ultrasonografi pada saat ini menjadi pemeriksaan yang menjadi pilihan utama di samping penggunaannya yang sangat mudah dan non invasif tetapi juga dari segi perhitungan biaya yang relatif rendah. ${ }^{22}$ 
Penilaian tentang derajat stenosis arteri sangat penting untuk menentukan rencana tindakan medis. Teknik pengikuran derajat stenosis yang sering digunakan pada saat ini adalah menurut yang digunakan pada penelitian NASCET. Penelitian ini pada dasarnya meneliti outcome tindakan carotid endarterektomi berdasarkan derajat stenosis berfdasarkan pemeriksaan ultrasonografi (Ferguson, 1999). Penelitian NASCET (North American Symptomatic Carotid Endarterectomy Trial) mendapatkan bahwa tindakan Carotid Endarterctomy memiliki hasil yang signifikan lebih baik dibandingkan dengan penatalaksanaan konservatif baik pada derajat stenosis $70 \%$ ke atas ataupun yang dengan derajat stenosis $50-69 \% .^{4}$

Mobilitas plak.

Adakalanya fibrous plak tipis yang menyelimuti area hipoekoik tampak bergerak seiring dengan denyut arteri.

\section{SIMPULAN}

Pencitraan plak aterosklerosis dengan ultrasonografi konvensional merupakan teknik yang relative mudah, murah dan noninvasif dengan level sensitifitas dan spesifisitas yang setara dengan modalitas pemeriksaan pencitraan lainnya. Pencitraan ultrasonografi plak pada arteri karotis meliputi lokasi plak, ukuran plak, permukaan plak, ekogenitas plak, komposisi plak dan mobilitas plak.

\section{REFERENSI}

1. Suroto (2012). Aterosklerosis. Dalam: aterosklerosis, Trombosis dan Stroke Iskemik. Surakarta: UNS Press, pp:1-5.

2. Gofir A. (2011). Definisi Stroke, Anatomi, Vaskularisasi Otak, dan Patofisiologi Stroke.Dalam :Manajemen Stroke. Ed 2. Yogyakarta : Pustaka Cendekia Press, pp :19-35
3. Woo S, Joh J, Han S, Park H Prevalence and risk factors for atherosclerotic carotid stenosis and plaque. Medicine. 2017;96(4):e5999.

4. Grant GE, Melany M (2012). Ultrasound Assessment of Carotid Stenosis. Dalam: Polak JF, Pellerito JS (eds), Introduction to Vascular Ultrasound. Philadphia: Elsevier, pp:158-73.

5. Hall HA, Bassiouny HS (2012). Pathophysiology of Carotid Atherosclerosis. Dalam: Nicolaides Et Al(eds). Ultrasound and Carotid Bifurcation Atherosclerosis. London: Springer, 27-36.

6. Bazan HA, Smith TA, Donovan MJ, Sternbergh WC III. Future management of carotid stenosis: Role of urgent carotid interventions in the acutely symptomatic carotid patient and best medical therapy for asymptomatic carotid disease. Ochsner J. 2014;14:608-615

7. Brott TG, Halperin JL, Abbara S, Bacharach JM, Barr JD, Bush RL, et al

(2011).ACCF/AHA/AANN/AANS/ ACR/ASNR/CNS/SAIP/SCAI/SIR/S NIS/SVM/SVS guideline on the management of patients with extracranial carotid and vertebral artery disease. J Am Coll Cardiol. 2011;57:16-94

8. Harloff A (2012). Carotid Plaque Hemodynamic. Interventional neurology, 1: 44-54.

9. Polak JF (2012). Normal Findings and Technical Aspects of Carotid Sonography. Dalam: Introduction to Vascular Ultrasound. Philadphia: Elsevier, pp:136-54.

10. Japan Society of Ultrasonic In Medicine (2009). Standard Method for Ultrasound Evaluation of Carotid 
Artery Lessions. J Med Ultrasonics. 36: 501-18.

11. Mozzini C, Roscia G, Casadei A, Cominacini L. Searching the perfect ultrasonic classification in assessing carotid artery stenosis: comparison and remarks upon the existing ultrasound criteria. Journal of Ultrasound. 2016;19(2):83-90.

12. Lee W (2014). General Principles of Carotid Doppler Ultrasonography. Ultrasonography, 33(1): 11-16.

13. Yan L, Zhou X, Zheng Y, Luo W, Yang J, Zhou $\mathrm{Y}$ et al. Research progress in ultrasound use for the diagnosis and treatment of cerebrovascular diseases. Clinics. 2019;74..

14. William MM (2001). Variant and Abnormality Extracranial Carotid System. In: Vascular Ultrasound of the Neck. Philadelphia: LWW, hal:88-89

15. Hutchinson SJ, Holmes KC (2012). Carotid artery disease in principles of vascular Ultrasound. Elseviel. Philadelphia, hal 19-22.

16. Adlova R, Adla T. Multimodality Imaging of Carotid Stenosis. International Journal of Angiology. 2015;24(03):179-184.

17. Virmani R, Burke A, Ladich E, Kolodgie FD (2007). Pathology of Carotid Artery Disease. Dalam: Gillard J, Graves M, Hatsukami T, Yuan C. Carotid Disease. New York: Canbridge Unnivesity Press, pp:121.

18. Thorsson B, Eiriksdottir G, Sigurdsson S, Gudmundsson E, Bots $\mathrm{M}$, Aspelund $\mathrm{T}$ et al. Population distribution of traditional and the emerging cardiovascular risk factors carotid plaque and IMT: the REFINE-Reykjavik study with comparison with the Troms $\emptyset$ study.
BMJ Open. 2018;8(5):e019385. Owen DRJ, Lindsay AC (2011). Imaging of Atherosclerosis, 52: 2540.

19. Park T. Evaluation of Carotid Plaque Using Ultrasound Imaging. Journal of Cardiovascular Ultrasound. 2016;24(2):91.

20. Geraulakos G, Sabetal MM (2000). Ultrasonic Carotid Plaque Morphology. Achives of Hellenic Medicine, 17(2): 141-45.

21. Kyriacou E, Pattichis C, Pattichis M, Loizou C, Christodoulou C, Kakkos $\mathrm{S}$ et al. A Review of Noninvasive Ultrasound Image Processing Methods in the Analysis of Carotid Plaque Morphology for the Assessment of Stroke Risk. IEEE Transactions on Information Technology in Biomedicine. 2010;14(4):1027-1038.

22. Polak JF, Pellerito JS (2012). Normal Cerebrovascular Anatomy and Collateral Pathway. Dalam: Introduction to Vascular Ultrasound. Philadphia: Elsevier, pp: 128-35. 